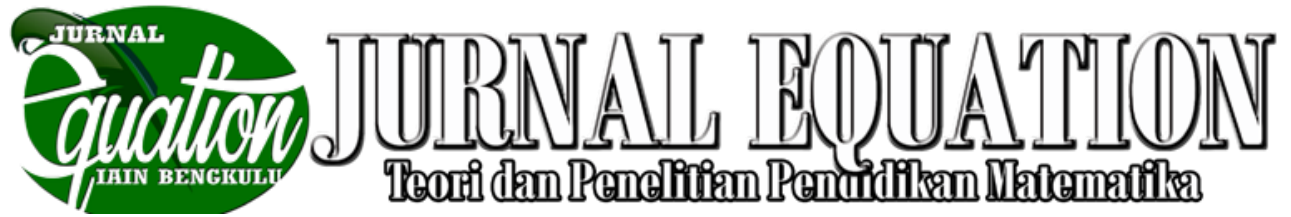

Volume 1 Nomor 2, September 2018, ISSN 2599-3291 (Cetak), ISSN 2614-3933 (Online)

\title{
Penggunaan Aplikasi Geogebra pada Pembelajaran Matematika Materi Poligon dan Sudut Sebagai Sarana Meningkatkan Kemampuan Siswa
}

\author{
Miftah Faradisa1), M. Sulistio Z.2), Yeni Astri Ayu'3) \\ Fakultas Tarbiyah dan Tadris, IAIN Bengkulu \\ miftahfaradisa@gmail.com
}

\begin{abstract}
ABSTRAK
Tujuan penulisan karya tulis ini adalah mengajak pembaca untuk mengetahui apa itu aplikasi GeoGebra, apa tujuan dan fungsi dari aplikasi GeoGebra itu sendiri serta penggunaan aplikasi GeoGebra dalam pembelajaran matematika. Adapun yang menjadi latar belakang tulisan ini adalah, karena di era teknologi yang semakin canggih saat ini, peserta didik sangat membutuhkan aplikasi yang dapat membantu belajar, bahkan aplikasi GeoGebra juga dapat menjadi bahan ajar bagi pengajar dalam pembelajaran matematika terutama di materi poligon dan sudut. Begitu pentingnya sebuah aplikasi yang dapat menunjang kemampuan belajar peserta didik. Maka dari itu penulis mengajak pembaca untuk mulai menggunakan dan mengaplikasikan aplikasi GeoGebra dalam pembejaran matematika.
\end{abstract}

Kata Kunci : aplikasi GeoGebra, pembelajaran matematika, poligon dan sudut.

\section{PENDAHULUAN}

Matematika merupakan salah satu pembelajaran yang kurang disenangi dan sangat dibenci oleh sebagian murid, siswa dan bahkan mahasiswa. Matematika itu sendiri menjadi momok yang paling menakutkan oleh sebagian peserta didik baik pembelajarannya maupun tenaga pengajarnya.

Saat ini adalah era ICT (Information and Communication Technology). Seiring dengan itu saat ini sudah banyak software yang dapat dimanfaatkan untuk dunia pendidikan termasuk pendidikan matematika sekolah. Perkembangan teknologi yang pesat membuka peluang dan jalan baru dalam mengembangkan banyak hal, termasuk untuk mengembangkan dunia pendidikan. Saat ini telah banyak berkembang berbagai macam teknologi yang dapat dimanfaatkan untuk mengembangkan dunia pendidikan, termasuk untuk menunjang pembelajaran matematika yakni sebagai media pembelajaran matematika. Salah satu media pembelajaran yang saat ini berkembang demikian pesat adalah komputer dengan berbagai programprogram yang relevan. Salah satu program komputer yang dapat dimanfaatkan sebagai media pembelajaran matematika adalah program GeoGebra. GeoGebra merupakan salah satu software yang dapat membantu dalam pembelajaran matematika, bahkan juga dapat membantu dalam penulisan bahan ajar dan lebih hebat lagi dapat digunakan sebagai alat bantu untuk menyelesaikan soal. Begitu pentingnya peranan dan fungsi aplikasi GeoGebra untuk pembelajaran matematika, 


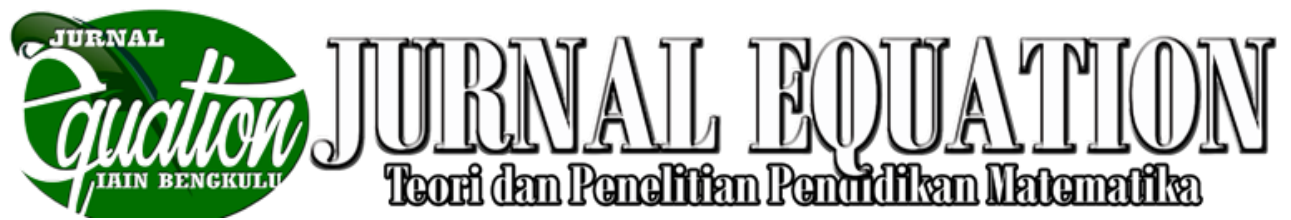

Volume 1 Nomor 2, September 2018, ISSN 2599-3291 (Cetak), ISSN 2614-3933 (Online)

maka tidak ada salahnya jika aplikasi GeoGebra sangat di butuhkan dalam pembelajaran matematika baik itu untuk bahan ajar ataupun untuk menyelesaikan soal.

Tujuan dari penulisan karya ilmiah ini yaitu untuk mengetahui penggunaan aplikasi GeoGebra pada pembelajaran matematika materi poligon dan sudut. Dan untuk mengetahui cara meningkatkan kemampuan pembelajaran matematika pada materi poligon dan sudut dengan menggunakan aplikasi GeoGebra.

\section{PEMBAHASAN}

\section{Aplikasi Geogebara}

1. Pengertian Geogebra

Geogebra merupakan salah satu program matematika dinamis untuk belajar dan mengajar matematika di sekolah. Geogebra dikembangkan oleh Markus Hohenwarter pada tahun 2001. Menurut Hohenwarter (2008), Geogebra merupakan program computer untuk membelajarkan matematika khususnya geometri dan aljabar. Program ini dapat dimanfaatkan secara bebas dan dapat diunduh di www.GeoGebra.org. Program GeoGebra melengkapi daftar program pembelajaran matematika yang telah ada sebelumnya seperti Maple, Mupad, dan Derive. Serta menambah khasanah program computer dibidang geometri selain CABRI, Geometry's sketchpad, WinGeom atau yang lainnya. Menurut Hohenwarter, GeoGebra dirancang untuk membelajarkan geometri, aljabar, statistic dan kalkulus sekaligus.

2. Manfaat belajar dengan GeoGebra

Menurut Dr. Ali Mahmudi (2010), pemanfaatan program GeoGebra memberikan beberapa keuntungan, diantaranya adalah sebagai berikut:

Lukisan geometri yang dihasilkan akan lebih teliti dan cepat jika dibandingkan dengan menggunakan cara manual (pensil, penggaris atau jangka).

Fasilitas animasi dan gerakan manipulasi pada GeoGebra dapat memberikan pengalaman visual yang lebih jelas.

Dapat dimanfaatkan sebagai bahan evaluasi untuk memastikan bahwa lukisan yang dibuat adalah benar.

Mempermudah guru/siswa untuk menyelidiki atau menunjukkan sifat-sifat yang berlaku pada suatu objek geometri.

Sedangkan menurut Hohenwarter \& Fuch (2004), GeoGebra sangat bermanfaat sebagai media pembelajaran matematika dengan beragam aktivitas sebagai berikut:

a. Sebagai media demonstrasi dan visualisasi 


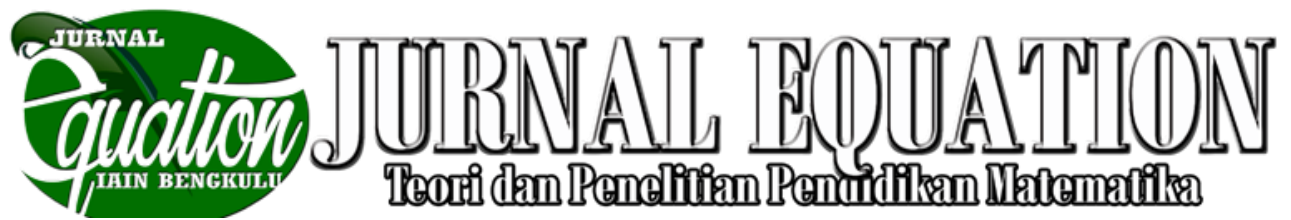

Volume 1 Nomor 2, September 2018, ISSN 2599-3291 (Cetak), ISSN 2614-3933 (Online)

Dalam hal ini, dalam pembelajaran yang bersifat tradisional guru memanfaatkan GeoGebra untuk mendemontrasikan dan memvisualisasikan konsep-konsep matematika tertentu.

b. Sebagai alat bantu konstruksi

Dalam hal ini GeoGebra digunakan untuk memvisualisasikan konsepkonsep matematika tertentu, misalnya mengkonstruksi lingkaran maupun lingkaran luar segitiga, atau garis singgung.

c. Sebagai alat bantu proses penemuan

Dalam hal ini GeoGebra digunakan sebagai alat bantu bagi siswa untuk menemukan suatu konsep matematis, misalnya tempat kedudukan titik-titik atau karakteristik grafik parabola.

Menu utama GeoGebra adalah: File, Edit, View, Option, Tools, Windows, dan Help untuk menggambar objekobjek geometri. Menu File digunakan untuk membuat, membuka, menyimpan, dan mengekspor file, serta keluar program. Menu Edit digunakan untuk mengedit lukisan. Menu View digunakan untuk mengatur tampilan. Menu Option untuk mengatur berbagai fitur tampilan, seperti pengaturan ukuran huruf, pengaturan jenis (style) objek-objek geometri, dan sebagainya. Sedangkan menu Help menyediakan petunjuk teknis penggunaan program GeoGebra. Berbagai menu selengkapnya disajikan pada gambar berikut ini.

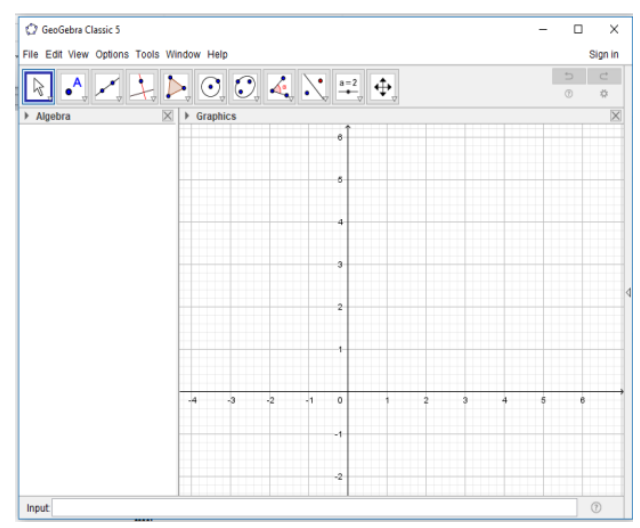

\section{Pembelajaran Matematika}

Matematika adalah mata pelajaran yang diajarkan dari sekolah dasar (SD) sampai dengan sekolah menengah atas (SMA). Matematika merupakan suatu ilmu yang penting dalam berbagai disiplin ilmu dan memajukan daya pikir manusia. Karena itu, untuk menguasai dan memanfaatkan teknologi masa depan diperlukan penguasaan matematika yang kuat sejak dini.

Matematika juga tidak dapat dilepaskan dari perkembangan peradaban manusia. Ini berarti matematika berkembang sejalan dengan kemajuan peradaban manusia. Kemajuan ini sangat dipengaruhi oleh tingkat kemajuan penerapan matematika oleh kelompok manusia itu sendiri. Dengan kata 


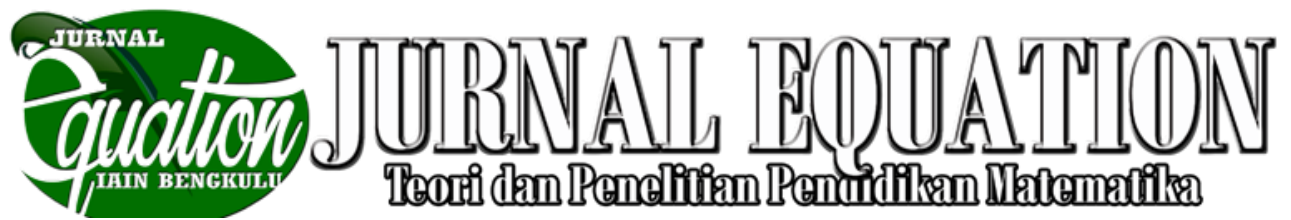

Volume 1 Nomor 2, September 2018, ISSN 2599-3291 (Cetak), ISSN 2614-3933 (Online)

lain suatu bangsa yang menguasai matematika dengan baik akan mampu bersaing dengan bangsa lain. Dalam kenyataannya, dapat dikatakan bahwa matematika memiliki peranan besar sebagai alat latihan otak agar dapat berpikir logis, analitis, dan sistematis sehingga mampu membawa seseorang, masyarakat, ataupun bangsa menuju keberhasilan.

Menurut konsep komunikasi, pembelajaran matematika adalah proses komunikasi fungsional antara siswa dengan guru dan siswa dengan siswa dalam rangka perubahan sikap dan pola pikir yang akan menjadi kebiasaan siswa yang bersangkutan. Dalam arti sempit, proses pembelajaran adalah proses sosialisasi individu siswa dengan lingkungan sekolah, seperti guru, sumber atau fasilitas dan teman-teman siswa.

Jadi, pembelajaran matematika merupakan kombinasi fungsional antara siswa dengan guru dan siswa dengan siswa dalam rangka perubahan sikap dan pola pikir agar siswa memiliki kemampuan, pengetahuan dan keterampilan matematis yang bertujuan mempersiapkan siswa mengahadapi perubahan yang selalu berkembang.

\section{Poligon dan Sudut}

Poligon berasal dari kata poli yang berarti banyak dan gonos yang berarti sudut. Secara harfiahnya, poligon berarti banyak Miftah Faradisa

Penggunaan Aplikasi... sudut. Namun arti sebenarnya adalah rangkaian titik-titik secara berurutan sebagai kerangka dasar pemetaan.

Poligon disebut juga segi banyak. Segi banyak adalah suatu kurva sederhana tertutup yang dibentuk oleh (terdiri atas) segmen garis- segmen garis. Segmen garissegmen garis yang telah membentuk segi banyak disebut sisi.

Poligon adalah gabungan ruas garis dari bagian yang bertemu hanya di titik akhir sehingga (1) sebesar dua ruas garis bertemu di satu titik, dan (2) Tiap ruas garis bertemu tepat dua ruas garis lainnya.Poligon dinamai dengan memakai jumlah dari sisinya. Contoh segitiga-3 sisi, segiempat-4 sisi, segilima-5 sisi, segienam-6 sisi, segitujuh-7 sisi, segidelapan-8 sisi,. Sebuah polygon dengan sisi n dapat disebut segi-n.

Sementara sudut adalah gabungan dari dua sinar, memiliki titik akhir yang sama. Titik akhir disebut verteks dari sudut dan sinar disebut sisi sudut. Berdasarkan besarnya sudut, sudut dibagi beberapa macam yaitu sudut lancip, sudut siku-siku, sudut tumpul dan sudut refleks. Sudut lancip adalah sudut yang memiliki besar sudut kurang dari $90^{\circ}$, sudut siku-siku adalah sudut yang memiliki besaran sudut $90^{\circ}$, sudut tumpul adalah sudut yang memiliki besar sudut lebih dari $90^{\circ}$ tetapi kurang dari $180^{\circ}$, sudut refleks adalah sudut 


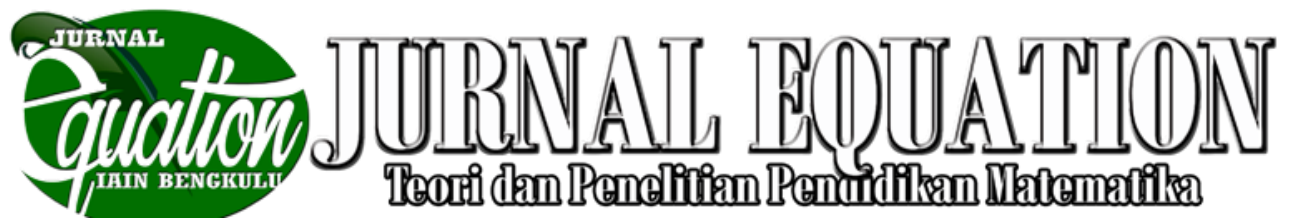

Volume 1 Nomor 2, September 2018, ISSN 2599-3291 (Cetak), ISSN 2614-3933 (Online)

yang memiliki besaran sudut lebih dari $180^{\circ}$ tetapi kurang dari $360^{\circ}$.

\begin{tabular}{|c|c|c|c|}
\hline Actatengle (inse) & Right argh thenat) & 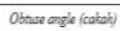 & Refer orge (roflest) \\
\hline & $x=90^{\circ}$ & & $180<x<360^{\circ}$ \\
\hline
\end{tabular}

Indikator Kemampuan Pembelajaran Poligon dan Sudut

Indikator dari pembelajaran poligon dan sudut antara lain:

- Menjelaskan pengertian poligon dan sudut

- Macam-macam poligon dan sudut

\section{METODOLOGI PENULISAN}

Jenis penelitian yang digunakan dalam penulisan karya ilmiah ini adalah metode secara langsung atau tinjauan pustaka, yakni dengan cara mengkaji berbagai referensi yang berhubungan dengan aplikasi GeoGebra dan pembelajaran matematika tentang poligon dan sudut.

\section{HASIL DAN PEMBAHASAN}

Penggunaan Aplikasi GeoGebra pada Pembelajaran Matematika padaMateri

\section{Poligon dan Sudut}

GeoGebra merupakan salah satu program matematika dinamis untuk belajar dan mengajar matematika di sekolah. Geogebra merupakan program komputer untuk membelajarkan matematika khususnya geometri dan aljabar. Geogebra dikembangkan oleh Markus Hohenwanter pada tahun 2001.
Geogebra adalah aplikasi atau software dengan ide dasar menggabungkan geometri, aljabar dan kalkulus yang dapat digunakan untuk belajar dan mengajar ditingkat SD, SMP, SMA dan Universitas (Hohenwanter, 2008). GeoGebra dapat digunakan sebagai media pembelajaran, alat bantu membuat bahan ajar, dan menyelesaikan soal matematika. Siswa dapat membuat konstruksi masalah matematika sendiri dan memecahkannya menggunakan GeoGebra. GeoGebra membuat matematika menjadi lebih interaktif dan menarik. GeoGebra diciptakan untuk membantu siswa memperoleh pemahaman yang lebih baik dalam matematika terutama pada materi poligon dan sudut. Melalui Geogebra siswa dapat membuat konstruksi dari awal mereka sendiri, sehingga mereka memiliki kesempatan untuk memecahkan masalah dengan menciptakan model dan menyelidiki hubungan matematik. Dengan menggunakan aplikasi GeoGebra siswa dapat dengan mudah memvisualisasikan pada pembelajaran poligon dan sudut. dengan menggunakan GeoGebra siswa dapat menentukan besaran sudut yang ada di dalam poligon.

Secara umum ada tiga bagian utama dari tampilan aplikasi GeoGebra yaitu input bar, tampilan aljabar, dan tampilan grafik. Input bar untuk membuat objek, persamaan, dan 


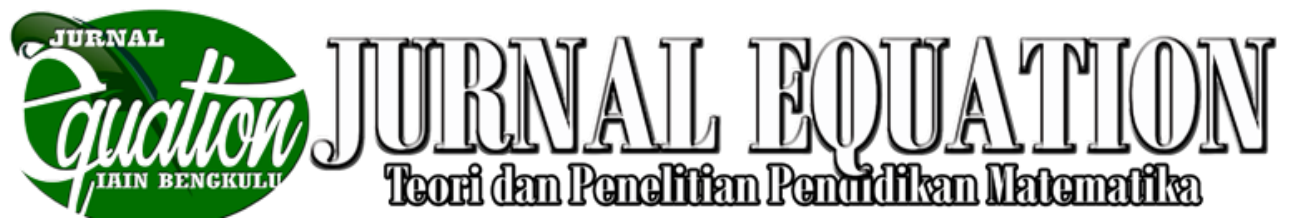

Volume 1 Nomor 2, September 2018, ISSN 2599-3291 (Cetak), ISSN 2614-3933 (Online)

fungsi baru yang akan ditampilkan. Tampilan aljabar digunakan untuk menampilkan dan mengedit semua objek yang akan dibuat. Tampilan grafik digunakan untuk menampilkan dan mengedit objek dan grafik dari suatu fungsi.

Selanjutnya pada tampilan GeoGebra ada alat konstruksi yang berguna untuk membuat fungsi, persamaan yang akan kita buat, berikut alat kosntruksi pada GeoGebra:

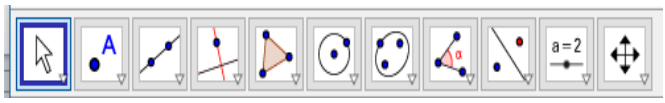

Melalui penggunaan aplikasi GeoGebra dapat meningkatkan beberapa kemampuan siswa. Diantaranya yaitu kemampuan penalaran matematis siswadan meningkatkan kemampuan keterampilan siswa dalam menggunakan software GeoGebra. Peningkatan kemampuan penalaran matematis melalui penggunaan GeoGebra dikarenakan aplikasi GeoGebra memungkinkan siswa melakukan pembelajaran matematika materi poligon dan sudut atau lainnya secara mandiri. Dan melalui tampilan visual dan geometris dari konsep matematika di Geogebra mendorong siswa untuk aktif berpikir dalam menemukan hubungan serta menarik kesimpulan dari objek dan konsep matematis. Dan dengan fitur yang ada di GeoGebra, siswa dapat berlatih mempresentasikan ide dan menyusun bukti matematika serta menjelaskan ide yang diperoleh dari objek visual matematika.

\section{Kelebihan dari Aplikasi GeoGebra}

Kelebihan yang didapat dari aplikasi ini adalah: Free, dapat digunakan di berbagai sistem operasi (Windows, MacOS, Linux), dan didukung lebih dari 40 bahasa.Dan berita baiknya bahasa Indonesia termasuk di dalamnya. Easy to use. Setiap tombol dan syntax pada GeoGebra selalu disertai dengan instruksi dan bantuan penggunaan.

\section{KESIMPULAN DAN SARAN}

\section{Kesimpulan}

Dari penjelasan di atas dapat disimpulkan bahwa GeoGebra merupakan software yang mampu membantu kita dalam mengerjakan tugas matematika. Geogebra juga sangat cocok digunakan oleh para siswa atau mahasiswa karena penggunaannya yang mudah dan open source. GeoGebra merupakan hasil dari perkembangan teknologi. Dan GeoGebra juga dapat digunakan sebagai media atau sarana untuk meningkatkan kemampuan matemats siswa.

\section{Saran}

Berdasarkan penjelasan di atas, maka kami merekomendasikan kepada para guru, dosen atau para pengajar lainnya untuk menggunakan aplikasi GeoGebra saat mengajarkan matematika terutama pada 


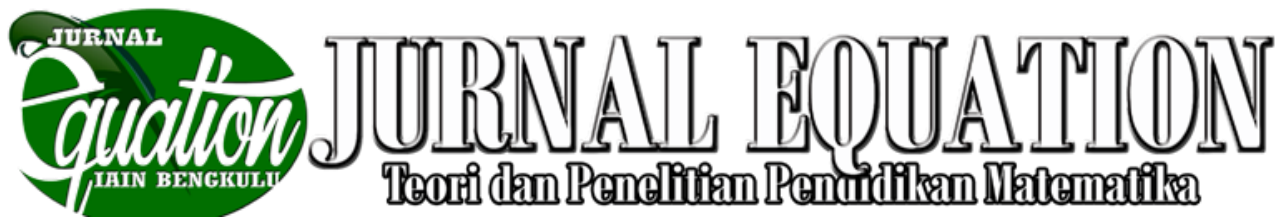

Volume 1 Nomor 2, September 2018, ISSN 2599-3291 (Cetak), ISSN 2614-3933 (Online)

materi aljabar, geometri dan kalkulus karena dengan menggunakan aplikasi GeoGebra maka siswa akan merasa tertarik untuk mengikuti kegiatan pembelajaran dan aplikasi ini juga mempermudah proses pembelajaran.

\section{DAFTAR PUSTAKA}

Anggraini Lena D. Makalah Geogebra. https://id.scribd.com. Diakses pada 4 November 2018.

Anonim. (2012). Poligon dan sudut. http://teorimath.blogspot.com.

Diakses pada 4 November 2018.
Barron. (2009). E-Z Geometry. New York: Hauppauge.

Hohenwarter, M., et al (2008). Teaching and Learning Calculus with Free Dynamic Matgematics Software GeoGebra.

Mahmudi, Ali. (2017). Pemanfaatan geogebra dalam pembelajaran Matematika. UNY.

Muchiyidin, Arif. (2017). Modul Praktikum Geometri dengan Menggunakan Geogebra.

Cirebon. 